\title{
The Contribution of Workplace Incivility and Psychological Capital toward Job Stress
}

\author{
Milha Shabir \\ Department of Business dministration, National Textile University, Faisalabad, Pakistan \\ Email: milha_shabir@hotmail.com \\ Muhammad Abrar (Corresponding Author) \\ Assistant Professor, Department of Business Administration, \\ Faculty of Management Science, National Textile University, Faisalabad, Pakistan \\ Email: abrarphd@gmail.com \\ Sajjad Ahmad Baig \\ Assistant Professor, Department of Business Administration, \\ Faculty of Management Science, National Textile University, Faisalabad, Pakistan \\ Email: sajjad.baig@hotmail.com

\begin{abstract}
Mehwish Javed
Department of Business Administration, National Textile University, Faisalabad,

Pakistan

Email: wish_onenonly@yahoo.com
\end{abstract}

Doi:10.5296/ijhrs.v4i2.5786

URL: http://dx.doi.org/10.5296/ijhrs.v4i2.5786

\begin{abstract}
Previously, a great stream of research is based on the study of workplace incivility and its impact on outcomes, but a very few studies were conducted to check the effect of different moderators and mediators that could affect the relationship of workplace incivility with outcomes. With the sample $(\mathrm{N}=100)$ of employees from telecommunication companies of Pakistan, current study carries out with the aim of exploring the effect of workplace incivility and psychological capital on job stress. We also examined the moderating influence of the psychological capital in the workplace incivility and job stress relationship. Self-administered surveys were conducted and results of the questionnaire were analyzed by using SPSS software. Results provided good support for the proposed hypothesis. While workplace incivility was associated positively with job stress, psychological capital had a significant relationship with job stress. As hypothesized, the result for the moderation was counter to expectation where incivility, job stress relationship was stronger when psychological capital was high. Our study provides a few approaches into the generalizability ideas and concepts such as workplace incivility and psychological capital in Faisalabad. However, there is a need to make further efforts to expand and test complex models in different cultural contexts.
\end{abstract}


Keywords: workplace incivility; psychological capital; job stress.

\section{Introduction:}

Over the past decade, researchers were documented the harmful effect of interpersonal abuse and mistreatment in the workplace (Caza \& Cortina, 2007, Willness et al., 2007; Cortina et al., 2001; Lim \& Cortina, 2005; Porath \& Pearson, 2010). Interpersonal mistreatment refers to behaviors such as aggression in verbal (e.g., curse), lack of respect (e.g., public humiliation, and interruption), and isolation (e.g., main task). Interpersonal mistreatments directly affect employees, and organizational outcomes (Caza \& Cortina, 2007; Willness et al., 2007; Cortina et al., 2001; Porath \& Pearson, 2010).

However, in past year has interest increased in "milder" forms of interpersonal mistreatment, which is known by different names: emotional abuse, intimidation, workplace abuse, and workplace in-civility (Cortina et al., 2001). Different forms of the interpersonal mistreatment such as workplace incivility. The literature has shown particular views as an important aspect of incivility (Cortina \& Magley, 2009). Incivility in the workplace, found a relatively new topic within the interpersonal mistreatment research, one of the most common type of antisocial behavior in the regulatory environment.

The basic argument is that the lack of civility in some cases, not "general" at all, but represents the modern gender and racial discrimination in the workplace (Cortina, Kabat-Farr, Leskinen, Huerta, \& Magley, 2011). Namely, with the increase of taboos policies and law that prohibit discrimination against certain groups in society, acknowledged intentions and efforts to distance women and minorities in organizational life tolerable anymore (Cortina, 2008; Cortina, Leskinen, Huerta \& Magley, 2011).

However, the difference mask (though unintentionally) back from daily actions rudeness and still maintain an objective viewpoint. This would be consistent with research showing that biases continue secret society in the overall and in particular organizations

The prominent feature of workplace incivility, disrespect the rules of the organization (Pearson et al., 2001), or a violation of the "network contractual and moral obligations that people stay" (Lim et al., 2008). When uncivilized incidents happen, particular employees do not explain along the same route. Although the basic standard in respect reactions organizations, workers has different (if only slightly) to understand these rules and violated the types of behavior among people.

\section{Workplace Incivility:}

\section{Review of Literature}

Workplace incivility has been defined by Andersson and Pearson (1999) as "the low intensity deviant with ambiguous intent to harm the target, in violation of workplace norms of mutual respect" (p. 457). The general definition of incivility is uncivil, rude, or discourteous behavior. Uncivil behaviors are characteristically rude and discourteous, displaying a lack of regard for others (Cortina, 2008; Ismail \& Zakuan, 2012; Andersson \& Pearson, 1999). Incivility related to rejected preference. Incivility demonstrated by disrespectful behavior. It undermines the dignity, lordliness and self-esteem of employees, suffering unnecessary conditions (Cortina, 2008; Ismail \& Zakuan, 2012). 
Incivility focused on gender and race. Interpersonal mistreatment in the workplace can based on social dimensions like that age, disability status and sexual orientation. In an organization, workplace incivility is increasing the effect in externally and internally. Workplace incivility is a low level form of deviance in which workplace norms of respect are violated (Cortina et al., 2011).

A human being targeted with rude and uncivil work behavior related to high job stress, dissatisfaction, absenteeism, distraction and low productivity, creativity, job satisfaction, job performance, organizational citizenship behavior and cooperation and lose the commitment and peoples leave the organization (Cortina et al., 2001; Lim, Cortina \& Magley, 2008; Pearson et al., 2000). Even employees who only the experience incivility another (e.g., seeing the mistreatment of colleagues) show low job commitment and satisfaction and greater turnover intention and job burnout (Cortina et al., 2011).

Cortina et al., 2001 differentiate between two classes of deviant behavior (a) directed to toward organization (b) directed toward Co-workers. Workplace incivility may be differentiating abusive supervision and petty tyranny. Both abusive and petty tyranny refers to supervisors or leader mistreatment of subordinates (Taylor, 2010). Workplace incivility is negatively worked related mental health and physical outcomes. The workplace is affecting on the employee's performance, satisfaction, well being and employee attitudes (Cortina et al., 2001.

Literature suggests that these forms of low intensity verbal abuse are more general place in the job environment (Sakurai, 2011). The second, the intent behind the acts of incivility are ambiguous. Can be the instigators of incivility behave in an uncivil manner as a means to harm the organization, goal, to advantage themselves or may inadvertently conscious (Sakurai, 2011).

Some Common Examples of workplace incivility such as disrupt the meeting (coming in late, ignoring the others and inappropriate behavior) and interrupting and neglecting others, talking down to others, not listening, withholding information, breaking equipment and paying little attention or showing interest in others' opinions and passing blames for own mistakes and avoiding anyone (Ismail, \& Zakuan, 2012).

Incivility in the workplace often well known from other forms of interpersonal deviance such as abusive supervision, and workplace bulling based on two characteristics (Sakurai, 2011). The first, consisting of incivility low intensity of interpersonal mistreatment. In other words, if the deviation between persons classified along a continuum of intensity or severity, incivility would comprise lower closing stages of this continuum (Sakurai, 2011).

Incivility in the workplace is that the problem becomes more important and relevant for employees and organizations. With more and more jobs in the services become based in the United States, it is inevitable for most of the staff working in isolation, and thus avoid unpleasant interactions with all their colleagues as well as' with clients and customers (Cortina, Magley, Williams, \& Langhout, 2001).

\section{Psychological Capital:}

Psychological capital is defined as "One's positive assessment of circumstances and chance for success based on tenaciousness and motivated effort” (Luthans et al., 2007; Harms and 
Luthans, 2012). The study of positive organizational behavior first time introduced in the Journal of Organizational Behavior about 12 years ago and considerable attention through its major construct of psychological capital (Harms \& Luthans, 2012). Positive psychological capital is a multidimensional construct of an individual as characterized by high hope, optimism, self-efficacy and resilience. Taken together, four components of psychological capital resources are the thread of implicitly reflecting (Luthans et al., 2007; Harms \& Luthans, 2012).

Self-efficacy and hope are important factors than resilience and optimism in foreboding organizational citizenship behavior and attitudes. Self-efficacy and optimism related to health. Three facets of psychological capital, hope are a strong facet of work related outcomes and self-efficacy is share the strongest underlying common denominator (Abbas et al., (2012).

In addition, keep in view the relevance of psychological capital with coping, creativity and innovation; we test for the impact of psychological capital of supervisory rated innovative performance and job stress. Psychological capital differentiated from human resources, physical or technological resources and financial resources (Luthans et al., 2007).

In prior research, positive psychological capital further positive work results and cut back the counterproductive work behavior (Avey et al., 2009; Luthans et al., 2007). Psychological capital is helping in facilitating positive organizational change and moderating the relationship between incivility and job stress.

Recently, scholarly research in the area of positivity of organizational behavior taking into consideration that there is need to be focused on the individual's well being and his positive strengths at the workplace (Abbas et al., (2012). Conducting this type of positive psychological research resulted with the factors that focused on positives within the people rather than traditional research that focused only on the negatives within the people (Abbas et al., (2012).

This is not the equivalent of psychological capital organize the implied knowledge that employees and managers to build over time by putting in their time and delve into the process of socialization. In other words, psychological capital is more than just important to know how things are going (Luthans, Youssef, \& Avolio, 2007b).

\section{Hope:}

Hope is a one of the important component of positive organizational behavior. Hope includes Pathways (I am able to produced the routes to my goals), Agency (I am able to initiate and sustain movement along those pathways). It is not cognitive and thought. It has volitional and effective. It has effects on emotion and will. It's not desire some unrealistic wishes but reasonable expectation. It is reality and anticipates. Hope is longer and believing in something that is sure but sat least possible (Clarke, 2003). Hope positivity affects multiple life domains and positively related to health outcomes and physical health (Robinson \& Snipes, 2009). Adults having high hope so utilizing more adaptive problems solving and changing behaviors (Robinson \& Snipes, 2009).

Hope is the anticipation of student's high achievement across all educational approaches (Robinson \& Snipes, 2009). Hope also anticipates choice study skills and the aliments of goals in opposing academic situations (Robinson \& Snipes, 2009). Admitting the relationship 
between hope and academic achievement is well established, hoping beyond ideology into the white population is mostly non-existent and additional research is needed (Robinson \& Snipes, 2009). Which is clearly false assumptions course to expect or at least hope it is not likely a false or foolish optimist called on (Clarke, 2003).

\section{Optimism:}

Optimism is the second component of the psychological capital (Robinson \& Snipes, 2009). Optimism is a moderate belief involving view process relates positive thinking and holding a positive attitude to life situations and events (Robinson \& Snipes, 2009). Optimism is a general expectation of positive consequence that a related to greater success in achieving goals and optimism viewed as a foundation for well being across life domains (Robinson \& Snipes, 2009).

Optimism is influential in psychological adjustment, educational, occupational, and positively related to outcomes like that coping strategies, accomplishment, achievement and adjustment to college (Robinson \& Snipes, 2009). Optimism purportedly influences the situation specific peoples' thoughts when people are pursuing a goal.

Optimism is expecting a positive outcome in any given goal pursuit and whereas pessimists expects a negative outcome. Positive expectations set a positive emotion and negative expectations set a negative emotion (Rand, 2009). Optimism focuses on the positive outcome but paths identify the routes to achieve the outcomes.

\section{Self-Efficacy:}

Self-efficacy is people's confidence in their ability to achieve a specific goal in a specific situation. Peoples beliefs about their capabilities to produce designated levels of performance that exercise influence over events that affect their lives, determines how people feel, think, motivate themselves and behave (Jude, Jackson, Shaw, Scott, \& Rich, 2007). In previous research, self-efficacy is a considerable impact on performance results (Luthans et al., 2010). Efficacy differs from the other positive psychological constructs in important ways. Self-efficacy is the judgments of the personal capability and self-esteem is the judgment of self worth. Self-efficacy is one's capabilities to organize and execute the courses of action required to manage prospective situations (Robinson \& Snipes, 2009; Abbas \& Raja, 2011). Previous research shows that self efficacy anticipate various important job related outcomes, that includes, job performance, job attitude, job stress, and training competencies (Jude et al., 2007).

A previous research suggests the importance of self-efficacy among American African students for achievement and well-being (Robinson \& Snipes, 2009). Some study of self-efficacy on childhood disability on parents. Low self-efficacy is associated with symptoms of depression and anxiety, additionally to lower levels of well being (Karademas, 2006).

\section{Resilience:}

Resilience is the last component of positive psychological capital defined as "positive psychological capacity to rebound, to 'bounce back' from adversity, stress, conflict, failure or 
even positive change, uncertainty, progress and increase in responsibility" (Abbas \& Raja, 2011). Therefore, resilience characterized by coping responses to not only adverse events, but also to extreme positive events as well. Resilient people are the ability to positively adapt new things during risk, adversity and cope (Abbas \& Raja, 2011).

Resilient people tend to bounce back from difficult or failure and setback. Resilient person is peculiar, energetic toward life and open to new experience. Resilient persons are humorous and use of the creative geographic expedition (Abbas \& Raja, 2011). These individuals are to ability for adaptation and adjustment of positive change (Luthans et al., 2007; Abbas \& Raja, 2011).

Resilient leader is likely to encourage themselves and subordinates to take the risk and to exhibit innovative behaviors (Abbas \& Raja, 2011). Resilience is the difference between recovering after adversity and remains distressed and do not move ahead. In many research, resilience stemmed from clinical psychology where the healer focuses interference on both level assets and risk factors (Luthans et al., 2010). Resilience thinking based upon positive beliefs, characterized by capacity to see another point of view, thinking that is flexible and accurate, creative problem solving and ability to continue with daily life, despite obstacles.

\section{Outcome:}

\section{Job Stress:}

Job stress has been marked in the search for work and one of the occupational hazards and the most dangerous in the modern era in the industrialized countries. For work related stress affects health leased $50-80 \%$ of mental illness is the nature or related stress (Jamal \& Baba, 2000). Job stress influenced from one perception.

Although the perception of the individual affects the pressures of work related, but the features and time and excessive workload, long working negative effects have employees. Referred work related stress in the previous study to the demands and challenges caused by the impact of employee represent (Ching et al., 2011).

Work related stress is compared to always negative, and employee well being, job satisfaction, and organizational commitment. In addition, associated work related negatively with stress job satisfaction, and organizational commitment (Ching et al., 2011). Stress direction at work, and negatively related to job satisfaction, and organization. Work related stress affects job satisfaction, and organization, in the meantime, director of physical and mental well invested (Ching et al., 2011).

Job stress is a main concern in the workplace and focus of many organizational researchers (Jamal \& Baba, 1992). Situation that creates tension and stress, such as technology, violence, and downsizing, are the part of the existing business environment. Additional sources of stress and anxiety in the workplace includes incompetent supervisor, role ambiguity and work overload, among other (Jamal \& Baba, 1992). 
Theory and Hypotheses:

Workplace Incivility and Workplace Outcome:

\section{Workplace Incivility and Job Stress:}

Workplace incivility associated with the employee's experience of frustration and intervention with the ability to achieve goals (Spector, 1998). This frustration seen as a form of experienced job stress, caused by environment stresses like that over plus workload demands. Employees respond to work stress with a negative emotional react anger, frustration that results in behavioral (strain), psychological, and physical (Penney \& Spector, 2005).

Job stress (positive and negative) expected to relate to a behavior strain reaction outcomes from cognitive effort, and emotional related to assessing work stresses, and process of coping (Lazarus and Folkman, 1984). Stress reactions hostility, fatigue, and exhaustion are decrease performance (LePine et al., 2005). High stress and workload are positively related to incivility and teamwork behaviors (LePine et al., 2005).

Hypothesis 1: Workplace incivility is positively related to job stress.

\section{Psychological Capital and Work Outcome:}

Psychological capital is negatively related to job stress. High psychological capital in persons is believed to own the cognitive capability of self-regulation those offers the opening, self discipline, and energy essential to reach one goal (Abbas et al., (2012).

Positive psychological capital resource capability to help the employees by innovative behaviors and helping the employees to put their efforts to reach the goals by using will power and way power to face many initial failures, problems, and setback.

The demands for innovation or creativity is high frustration, tenseness, and stress among employees, positive psychological capital is the potential to get by with stressful demand on one hand and on the other hand, development and implements ideas (Abbas, \& Raja, 2011).

The resources are delusional, cognitive, motivational, and affective components, which help to successful development and implement ideas in their workplace (Abba \& Raja, 2011). In any case, psychological capital persons, as the definition propose, own the cognitive capability of self-regulation that provide restiveness and initiative, and self-discipline to reach the goals (Abbas \& Raja, 2011).

Psychological capital, given persons more confidence and excite the positive thinking, which should result in low job stress. Based on above-mentioned literature, present study proposed that:

Hypothesis 2: Psychological capital is negatively related to job stress.

\section{Moderating effect of Psychological Capital on Workplace Incivility and job stress:}

This theory helps in defining the procedures by those resources like that psychological capital assists the persons in coping with stress (Abbas, et al., (in press). Self-efficacy beliefs depress problems behaviors, (e.g. Aggression, and depression) and achieve a greater grade (Abbas et 
al., (2012).

Highly efficacious and effective persons are less likely to expect a loss and failure of confidence when they faced uncertainties, negative feedback, difficulties, and setbacks. Psychological capital resources are capacities from the emotional, motivational bases, and cognitive, through which persons extenuate the malevolent effects of negatively (Abbas et al., (2012).

When persons comprehend organizational activities, and process to incivility driven, psychological capital is helping to minimize the salience of resource loss related to activities, to cope better the stressors, thereby reducing the incivility and job stress.

Hypothesis 3: Psychological capital is moderate the relationship between incivility and job stress, such that the relationships become weaker when psychological capital is high.

\section{Theoretical Framework:}

Figure 1.1 shows the proposed theoretical framework, which was study in current research.

\section{Conceptual model of the study:}

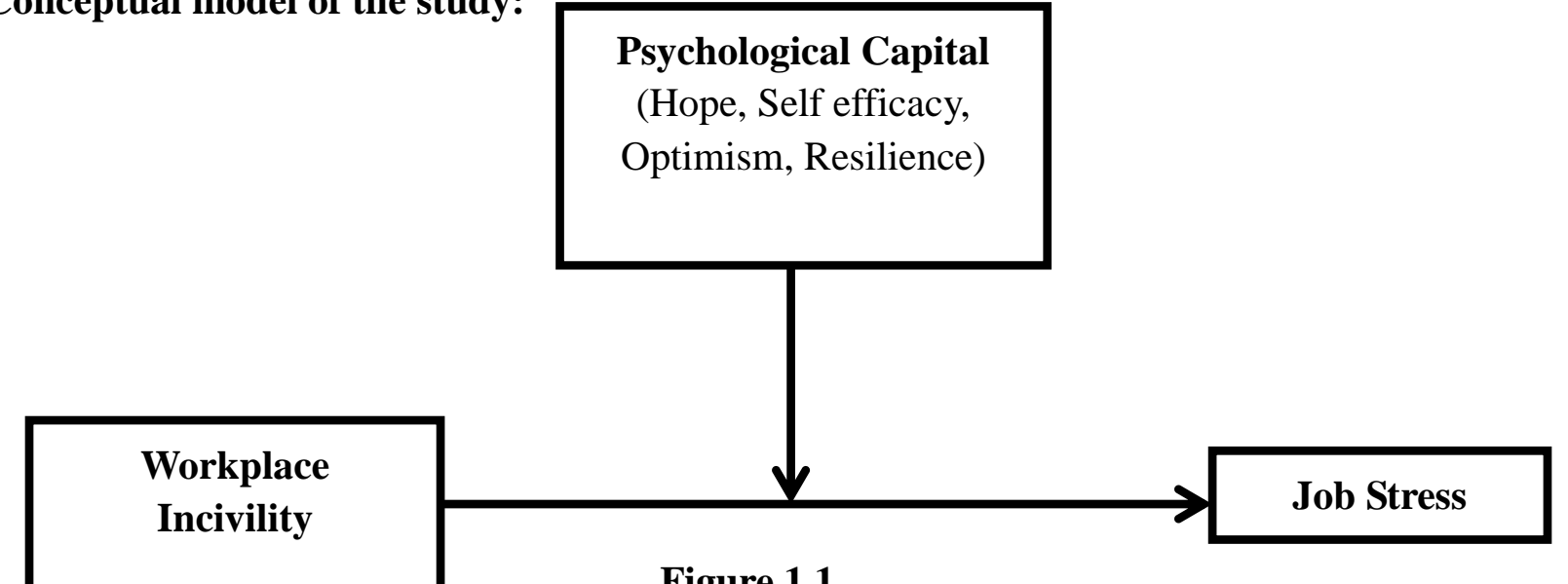

Methods:

\section{Sample and Procedure:}

The sample consisted of employees working in six well-established public and private sector organization. The research site included all telecom companies that were (Waird telecom, Mobilink, Ufone, Telenor, Zong and PTCL) were working in Faisalabad and customer services offices of Telecommunication Company in Faisalabad, and a large number of call centers of these telecoms were working in Faisalabad. Faisalabad is the third major city of Pakistan.

Surveys spread to employees working in clerical, secretarial, or top level positions, high level designated and trained worker in their respective organizational. Respondents completed self-report edition that contained items associated workplace incivility, psychological capital and job stress.

In adding, every one respondent reported her or his name, gender, age, organization, education, work experience and designation in the demographics component of the survey. Of 
the 160 distributed questionnaires, I received 100 completed self-responses. The response rate for telecommunication sector was $63 \%$. The greater part of respondents $81 \%$ were male had a mean age of 28 years $(\mathrm{SD}=6.37)$. The average work experience was $4.84(\mathrm{SD}=5.20)$.

\section{Measures:}

All measurements obtained from a self-report questionnaire. The responses to the entire variable were measured using a Likert type 5 point anchor

\section{Workplace Incivility:}

Workplace incivility measured by Workplace Incivility Scale (WIS) developed by Cortina et al., (2001). Workplace Incivility Scale 7 questions were assesses workplace incivility of participants with their supervisors and peers in during last five years. The sample questions were "Put you down or condescending to you", "Made demeaning or insulting remarks about you", "Addressed you in unprofessional terms" and so on. Responses were taken from five point scale ranges from " $1=$ strongly disagree", " $3=$ Neutral" and " $5=$ strongly agree". The reliability of workplace incivility was .95 .

\section{Psychological Capital:}

Luthans et al., (2007) used twenty-three item scales to measure psychological capital. Psychological capital questionnaire developed to measure four sub dimensions of positive psychological capital, these dimensions were hope, self-efficacy, optimism, resilience. Six items were use to assess hope, the sample items were "At the present time, I energetically pursue my work goals", "Right now I see myself as being pretty successful at work" and "At this time, and I am meeting the work goals that I have set for myself". Six items were use to assess self-efficacy. The sample items were "I feel confident analyzing a long term problem to find a solution", "I feel confident in representing my work area in meeting with management" and "I feel confident presenting information to a group of colleagues". Six items were use to assess resilience. The sample items were, "When I have a setback at work, I have trouble recovering from it, moving on", "I can be "on my own," so to speak, at work if I have to" and "I can get through difficult times at work because I have experienced difficulty before". Five items were use to assess optimism. The sample items were, "when things are uncertain for me at work, I usually expect the best", "I always look on the bright side of things regarding my job" and "I am optimistic about what will happen to me in the future as it pertain to work". Responses were taken on the five point Likert scale which ranges from " $1=$ strongly disagree", " $3=$ Neutral" and " $5=$ strongly agree". The internal consistency reliability of psychological capital was .85 .

\section{Job Stress:}

Research used 13 items to measure job stress. Parker and DeCotiis (1983) developed the scale. The sample items were "I felt nervous as a result of my job", "Working here leaves little time for other activities" and "I have too much work and too little time to do it in". Responses were taken on a five point Likert scale which ranges from " $1=$ strongly disagree", " $3=$ Neutral" and " $5=$ strongly agree". The reliability of job stress was .91 . 


\section{Control Variable:}

I used age, gender and work experience as control variables because of their possible effects on job outcome. Hence, I created a dummy variable ( 1 = "Male," 2 = "Female") to control for the impact of organizational type on the study reported below. Finally, I included gender, age, and organization type and work experience as controls for the entire outcome.

\section{Results:}

Table 1 shows the mean, standard deviations, and coefficient alpha reliability estimate and vicariate correlation among all measures. Table two shows regression analyses and table 3 shows main effects and moderated regression analyses.

\section{Correlations:}

The table 1 shows correlations between all the variables of the study that separated the sources and internal consistency of each scale. There were alpha coefficients along the core diagonal. According to Shultz and Whiteney (2005), and a common standard should be a good estimate of reliability, including the alpha coefficient is .70 or higher, at least. Preliminary analyzes indicate that workplace incivility was a significant negative, and moderate relationship with psychological capital. Additionally, psychological capital was

\begin{tabular}{llllllllll}
\hline & & M & SD & $\mathbf{1}$ & $\mathbf{2}$ & $\mathbf{3}$ & $\mathbf{4}$ & $\mathbf{5}$ & $\mathbf{6}$ \\
\hline $\mathbf{1}$ & Age & 28.81 & 6.375 & 1 & & & & & \\
$\mathbf{2}$ & Gender & 1.19 & 0.394 & $-0.239^{*}$ & 1 & & & & \\
$\mathbf{3}$ & Experience & 4.8497 & 5.20277 & $.823^{* *}$ & -0.142 & 1 & & & \\
$\mathbf{4}$ & Incivility & 2.9314 & 1.14403 & -0.176 & -0.012 & $-.292^{*}$ & $(\mathbf{. 9 5})$ & & \\
$\mathbf{5}$ & Psycap & 3.7591 & 0.41369 & 0.048 & 0.03 & 0.106 & $-.334^{* *}$ & $\mathbf{( . 8 5 )}$ & \\
$\mathbf{6}$ & Job Stress & 3.1838 & 0.79279 & $-.208^{*}$ & 0.019 & $-.283^{* *}$ & $.706^{* *}$ & $-.434^{* *}$ & $\mathbf{( . 9 1 )}$ \\
\hline
\end{tabular}

significant and negatively related to job stress and positively to organizational citizenship behavior. As hypothesized in this current study, workplace incivility has a significant and moderates the relationship with job stress, potentially providing support for hypothesis 1,2 , and 3.

\section{Table 1}

\section{Means, Standard Deviations, Correlations and Reliabilities:}

Note. $\mathrm{N}=100$; Alpha reliability are presented in parentheses. Psycap= psychological capital.

$*$ Correlation is significant at $\mathrm{p} \leq .05$

** Correlation is significant at $\mathrm{p} \leq .01$.

\section{Hypothesis Testing:}

linear regression model was used to test all main effect hypotheses (Hypotheses 1, 2, and $3)$. 


\section{Macrothink}

International Journal of Human Resource Studies

ISSN 2162-3058

2014, Vol. 4, No. 2

The relationships between the variables of interest in the hypothesis tested using correlation coefficient, regression and moderated regression. Hypothesis 1, workplace incivility was positively related to job stress $(\beta=.61, \mathrm{p}<.001)$. This result support Hypothesis 1 .

In the same way, Table 2 represents that Psychological capital was negatively related to job stress $(\beta=-.22, \mathrm{p}<.01)$. This result supports to Hypothesis 2.

Table 2

Results for Regression Analyses:

Job Stress

\begin{tabular}{llll} 
& B & $\mathbf{R}^{2}$ & $\Delta \mathbf{R}^{2}$ \\
\hline Step 1 & & \\
Control Variable & & 0.08 &
\end{tabular}

Step 2

$\begin{array}{llll}\text { Incivility } & .61 * * * & 0.55 & .46^{* * * *}\end{array}$

Psycap $\quad-0.22 * *$

Note. $\mathrm{N}=100$; Psycap $=$ psychological capital; Control variable $=$ job stress.

* Correlation is significant at $\mathrm{p} \leq .05$

$* *$ Correlation is significant at $\mathrm{p} \leq .01$

$* * *$ Correlation is significant at $\mathrm{p} \leq .001$.

Table 3

Results for Main Effects and Moderated Regression Analyses:

\section{Job Stress}

\begin{tabular}{llll}
\cline { 2 - 3 } & $\mathbf{B}$ & $\mathbf{R}^{\mathbf{2}}$ & $\Delta \mathbf{R}^{\mathbf{2}}$ \\
\hline Step 1 & & \\
Control Variable & & 0.08 &
\end{tabular}

Step 2

$\begin{array}{llll}\text { Incivility } & .61 * * * & 0.55 & 0.46 * * * \\ \text { Psycap } & -.22 * * & & \\ \text { Step 3 } & & & \\ \text { incivility×psycap } & .27 * * & 0.59 & 0.04\end{array}$

Note. $\mathrm{N}=100$; Psycap $=$ psychological capital; Control variable $=$ job stress.

$*$ Correlation is significant at $\mathrm{p} \leq .05$

$* *$ Correlation is significant at $\mathrm{p} \leq .01$

$* * *$ Correlation is significant at $\mathrm{p} \leq .001$. 


\section{Moderating Influence of Psychological Capital:}

I used moderated linear regression analyses to test hypotheses 3 (Cohen et al., 2003). Analysis of the moderated regression used to study the interactive impacts of workplace incivility and psychological capital and job stress. First, I entered control variables (age, gender and experience) in the first step. In the second step, I entered independent, and the moderator variable. Then, in the third step, I entered the product term of independent and the moderator variables, that if significant, hypothesis 3 confirmed.

Presented result in table 3 (step 3) show that, controlling for the effect of workplace incivility and psychological capital, interaction term of workplace incivility $\times$ psychological capital for job stress $(\beta=.27, \mathrm{p}<.01)$. This result supports to Hypothesis 3 .

\section{Discussion:}

Despite general conformity among researchers, observed evidence has exposed variations in the impact of workplace incivility on job stress.

My finding obviously support assertion that when incivility in the workplace, it increase the job stress $(\mathrm{r}=.61)$ and increases the possibility of leaving their organization. In addition, psychological capital was negatively related to job stress $(r=.22)$. These findings give good support for the idea of workplace incivility and psychological capital being detrimental to preferred outcomes at the workplace.

Consistent with earlier research, it considered incivility in the workplace generally related to employee attitudes (Cortina et al., 2001; S. Lim et al., 2008). Hypothesis 1, indicating that incivility in the workplace was significant related to job stress. Thus, it seems that in this case, the experiences aversive workplace such as incivility in the workplace can elicit negative feelings strong.

The results of my research support the idea that psychological capital has positive and helpful achieve on desired outcome like that job stress, but not on organizational citizenship behavior. In addition, I found support for the moderating influence of psychological capital in the workplace incivility and outcomes relationship. It was interesting, and contrary to my expectations, the negative association between workplace incivility and job stress was stronger when psychological capital was high. Similarly, my findings also show that people with high psychological capital was description job stress low, for high working pressure of individuals with mental psychological capita is low. These results provide initial support of features related to creativity and innovation among individuals in psychological capital high. Effects of stressors also tested out in the current study. Whether the sleeplessness is the effect of job stress or not, the analysis of this phenomenon reveals that, nearly half of the respondents relate sleeplessness to the job stress with less agreement on it. This concludes in the fact that sleeplessness is a problem that changes from person to person which makes it a more personality issue rather than that of the effect of job stressor.

\section{Theoretical Implication:}

Despite the theoretical appeal and the importance of theory in the workplace today, I found no any studies that examined the relationship between workplace incivility, psychological capital and job stress. The paper provides extensions to the theory of emerging by exploring 
the link of psychological capital with workplace incivility, and job stress.

The results of the current study have numerous theoretical implications. First, to my knowledge, this is first study to found a relationship between workplace incivility, psychological capital and job stress. In addition, discuss the positive psychological capital traits such as hope, optimism, self-efficacy and resilience.

In addition, the current study helps to establish a model of workplace incivility, psychological capital and job stress. I was examining the all variables. My finding that psychological capital moderating the relationship between workplace incivility and work related outcomes.

In addition, given that majority of the research in the organizations focused on addressing the causes and negative results of work related stress as an employee's anxiety, depression, burnout and fatigue (Harrison, 1998).

\section{Practical Implications:}

As discussed, mistreatment in the workplace in a variety of shapes with variable frequency, were bullied studies indicating $37 \%$ of American workers at work and approximately $15 \%$ of workers have been deal with to insulting and abusive supervision (Tepper et al., 2006). Incivility in the workplace, however, may happen in as many as $70 \%$ of the organizational (Cortina et al., 2001).

It is hoped that a better understanding incivility in the workplace leading to the development and growth of interventions to help alleviate the negative effects on organizations and employees. This study has suggestions for practicing managers. Since psychological capital is a comparable state and open to development, mangers can help their employees through training involvements to develop the psychological capital (Luthans et al., 2008).

Managers could deal with the contributing factors of workplace incivility in the ways such that by making clear procedures and policies, effective communication plans and information infrastructures and good governance, guidance and feedback, to reduce the effect of incivility on employees. Managers should reexamine there hiring and selection procedures, selection criteria should include checking personality characteristics that could add buffering effect in dealing with a stressor at workplace.

The staffs help to promote new ways to accomplish their duties and tasks. People can be seen psychological capital, because of the positive psychological resources as a competitive advantage for their organizations. In adding, managers must be careful in the allocation of managers is relatively cumbersome for those who are low psychological capital that these individuals are more possible to statement job stress.

The management should recognize that incivility in the workplace is a problem between its employees or workers. Incivility in the workplace may seem like trivial problem for management studies, but showed earlier that incivility in the workplace can be detrimental to many individual and organizational efforts (Porath, \& Pearson, 2010; Lim, Cortina, \& Magley 2008). Recognizing the significance of incivility in the workplace as a problem at work, and can take other measures to prevent acts of incivility occurrence.

Management can use different methods for the communicating of guideless and rules of incivility in the workplace. For example, they can establish guidelines and rules in place within the organization where all members of the organization can access them or they can 
write the guidelines and rules on the intranet Web page for the organization. Similarly, management can communicate the guidelines and rules in the public meetings of the orientation program for new employees and the organization.

\section{Future Research:}

Future research should be in this area examines the role of individual monitors and other contextual moderators in the connection between workplace incivility and job stress. For example, exploring the effect to five major attributes on the workplace incivility and job stress the relationship can provide insight into our understanding of the interaction of the individual and circumstances factors in determining the different behaviors and attitudinal outcomes.

Future researchers in this domain of research that focused on effects of workplace incivility across different nations, in future a direct comparison of culture-to-culture or western to non-western culture samples be used to dig into the moderating effect of cultural aspects.

Future studies, could effort to capture directly the point of view of the initiator, which require innovative and modern methods to overcome the desire for social bias. It would be also interesting to connect the instigators of their emotions, thoughts, and context shares, which are still testing the theory Cortina and help us to understand the social and personal factor or features that fuel incivility.

Apply this study on other cultures as well. The direct comparison of western and non-western cultures while studying this model. Take psychological capital as moderator with other stressors and check the effect. Take other personality contextual factors as moderator in the relationship of workplace incivility and job stress.

\section{Conclusion:}

The study reported demonstrates that the experience of incivility in the workplace affect employee well being and attitudes, may experience incivility in the workplace indirectly affect the feeling and employee behavior, and responses employee to incivility vary depending on the source (for example, coworker or supervisor incivility).

Initial research examined the direct relationship between incivility in the workplace and job stress. In particular, I have proposed and found support for the model linking incivility in the workplace to job stress through the moderating effects of psychological capital.

These results extend the investigation before by showing that the link between workplace incivility and job stress is more complex than previously thought, and thus contributes to the pursuit of the development of an integrated model to explore the impact of the negative effects of incivility.

My study provides a few approaches into the generalizability ideas and concepts such as workplace incivility and psychological capital in Faisalabad. However, there is a need to make further efforts to expand and test complex models in different cultural contexts. 


\section{References:}

Abbas, M., \& Raja, U. (2011). Impact of psychological capital on innovative performance and job stress. In 15th International Business Research Conference.

Abbas, M., Raja, U., Darr, W., \& Bouckenooghe, D. (2012). "Combined Effects of Perceived Politics and Psychological Capital on Job Satisfaction, Turnover Intentions, and Performance."Journal of Management, DOI: 10.1177/0149206312455243

Andersson, L. M., \& Pearson, C. M. (1999). Tit for tat? The spiraling effect of incivility in the workplace. Academy of Management Review, 24, 452-471.

Avey, J. B., Luthans, F., \& Youssef, C. M. (2010). The additive value of positive psychological capital in predicting work attitudes and behaviors. Journal of Management, 36(2), 430-452.

Cameron, K., Dutton, J., \& Quinn, R. E. (Eds.). (2003). Positive organizational scholarship: Foundations of a new discipline. Berrett-Koehler Publishers.

Caza, B. B., \& Cortina, L. M. (2007). From insult to injury: Explaining the impact of incivility. Basic and Applied Social Psychology, 29, 335-350.

Ching, W. S., Fatima, O. \& Maria, M. M. (2011). Work stress and outcome of stress among Malaysian managers. Psychology Research, 1(4), 270-277.

Clarke, D. (2003). Faith and hope. Australasian Psychiatry, 11(2), 164-168.

Cortina, L. M. (2008). Unseen injustice: Incivility as modern discrimination in organizations. Academy of Management Review, 33(1), 55-75.

Cortina, L. M., \& Magely, V. J. (2009). Patterns and Profiles of response to incivility in the workplace. Journal of Occupational Health Psychology, 14(3), 272-288.

Cortina, L. M., D. Kbat-Farr, E. M. Leskinen Huerta \& V. Magley (2011). Selective incivility as modern discrimination in organizations: evidence and impact. Journal of Management,

DOI: $10.1177 / 0149206311418835$

Cortina, L. M., Magley, V. J., Williams, J. H., \& Langhout, R. D. (2001). Incivility in the workplace: Incidence and impact. Journal of Occupational Health Health psychology, 6, 64-80.

Fineman, S. (2006). On being positive: Concerns and counterpoints. Academy of Management Review, 31(2), 270-291.

Goodrick, E., \& Salancik, G. R. (1996). Organizational discretion in responding to institutional practices: Hospital and cesarean births. Administrative Science Quarterly, 41(1), $1-28$.

Harms, P. D., \& Luthans, F. (2012). Measuring implicit psychological constructs in organizational behavior: An example using psychological capital.Journal of Organizational Behavior, 33(4), 589-594.

Harrison, S. J. (1998). Police organizational culture: using ingrained values to build positive organizational improvement. Public Administration and Management: An Interactive Journal, 3(2).

Ismail, I. R. B., \& D. Zakuan, Z. Z. M. (2012). Workplace incivility in Malaysia: A descriptive exploratory study. $3^{\text {rd }}$ International Conference on Business and Economic Research ( $3^{\text {rd }}$ ICBER 2012), ISBN: 978-967-5705-05-2. 
Jamal, M., \& Baba, V. V. (1999). Job stress and burnout among Canadian managers and nurses: an empirical examination. Canadian journal of public health, 91(6), 454-458.

Jude, T. A., Jackson, C. L., Shaw, J. C., Scott, B. A., \& Rich, B. L. (2007). Self-efficacy and work related performance: The integral tole of individual difference. Journal of Applied Psychology, 92(1), 107-127.

Karademas, E. C. (2006). Self-efficacy, social support and well-being: The mediating role of optimism. Personality and Individual Differences, 40(6), 1281-1290.

Lazarus, R. S., \& Folkman, S. (1984). Stress. Appraisal, and coping, 456.

LePine, J. A., Podsakoff, N. P., \& LePine, M. A. (2005). A meta-analytic test of the challenge stressor-hindrance stressor framework: An explanation for inconsistent relationships among stressors and performance. Academy of Management Journal, 48(5), 764-775.

Lim, S., \& Cortina, L. M. (2005). Interpersonal mistreatment in the workplace: the interface and impact of general incivility and sexual harassment. Journal of Applied Psychology, 90, 483-496.

Lim, S., Cortina, L. M., \& Magley. V. J. (2008). Personal and Workgroup Incivility: Impact on work and health outcomes. Journal of Applied Psychology, 93: 95-107.

Youssef, C. M., \& Luthans, F. (2007). Positive organizational behavior in the workplace the impact of hope, optimism, and resilience. Journal of Management, 33(5), 774-800.

Luthans, F., Avey, J. B., Avolio, B. J., \& Peterson, S. J. (2010). The development and resulting performance impact of positive psychological capital.Human Resource Development Quarterly, 21(1), 41-67.

Luthans, F., Avey, J. B., \& Patera, J. L. (2008). Experimental analysis of a web-based training intervention to develop positive psychological capital. Academy of Management Learning \& Education, 7(2), 209-221.

Luthans, F., Avolio, B. J., Avey, J. B., \& Norman, S. M. (2007). Positive psychological capital: Measurement and relationship with performance and satisfaction. Personnel Psychology, 60(3), 541-572.

Luthans, F., Norman, S.M., Avolio, B.J., \& Avey, J.B. (2008). The mediating role of psychological capital in the supportive organizational climate-employee performance relationship. Journal of Organizational Behavior, 2, 219-238.

Luthans, F., Youssef, C. M., \& Avolio, B. J. (2007). Psychological Capital. New York, NY: Oxford University Press.

Parker, D. F., \& DeCotiis, T. A. (1983). Organizational determinants of job stress. Organizational Behavior and Human Performance, 32: 160-177.

Pearson, C .M., Andersson, L. M., \& Porath, C. L. (2000). Assessing and attacking workplace incivility. Organizational Dynamics, 29 (2), 123-137.

Pearson, C. M., Andersson, L. M., \& Wegner, J. W. (2001). When workers flout convention: A study of workplace incivility. Human Relations, 54, 1387-1419.

Pearson, C., \& Porath, C. (2009). The cost of bad behavior: How incivility is damaging your business and what to do about it. Penguin.

Porath, C. L., \& Erez, A. (2007). Does rudeness really matter? The effects of rudeness on task performance and helpfulness. Academy of Management Journal, 50, 1181-1197.

Porath, C. L., \& Pearson, C. M. (2010). The cost of bad behavior. Organizational Dynamics, 


\section{Al Macrothink

39, 64-71.

Rand, K. L. (2009). Hope and optimism: Latent structures and influences on grade expectancy and academic performance. Journal of Personality, 77(1), 231-260.

Robinson, C., \& Snipes, K. (2009). Hope, optimism and self-efficacy: A system of competence and control enhancing African American college students academic well-being. Multiple Linear Regression Viewpoints, 35(2), 16-26.

Sakurai, K., \& Jex, S. M. (2012). Coworker incivility and incivility targets' work effort and counterproductive work behaviors: The moderating role of supervisor social support. Journal of occupational health psychology, 17(2), 150.

Shultz, K. S \& Whitney, D. J. (2005). Measurements theory in action: Case studies and exercise. Thousand Oaks, CA: Saga Publications, Inc.

Spector, P. E., \& Jex, S. M. (1998). Development of four self-report measures of job stressors and strain: Interpersonal conflict at work scale, organizational constraints scale, quantitative workload inventory, and physical symptoms inventory. Journal of Occupational Health Psychology, 3, 356-367.

Spector, P. E. (1998). A control theory of the job stress process. Theories of organizational stress, 153-169.

Tepper, B. J., Duffy, M. K., Henle, C. A., \& Lambert, L. S. (2006). Procedural injustice, victim precipitation, and abusive supervision. Personnel Psychology,59(1), 101-123.

Williams, L., \& Anderson, S. (1991). Job satisfaction and organizational commitment as predictors of organizational citizenship and in-role behaviors. Journal of Management, 17, 601-617.

Willness, C. R., Steel, P., \& Lee, K. (2007). A meta-analysis of the antecedents and consequences of workplace sexual harassment. Personnel Psychology, 60, 127-247. 